\title{
Лечение лимфом, ассоциированных с беременностью
}

\author{
${ }^{1}$ ГУО «Белорусская медицинская академия последипломного образования», Минск, Беларусь

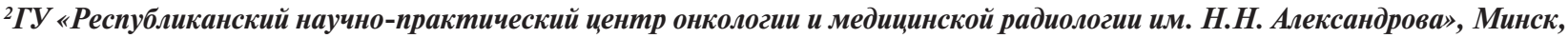 \\ Беларусь
}

Получено: 14.08 .2020

Принято в печать: 7.09.2020

DOI: $10.32471 /$ clinicaloncology.2663-466X.39-3.27367

Вступление. В современном мире активно изучаются возможности ведения беременности при раке, в том числе и лимфомах. Цель исследования. Оценить возможности пролонгирования беременности при лимфомах. Материалы и методы. Материалом для исследования послужили сведения о 23 пациентах с лимфомами, ассоциированными с беременностью, которым применяли системную химиотерапию во время гестации (основная группа). Контрольную группу составили 133 пациентки с лимфомой вне беременности. В группу сравнения вошли 74 здоровые беременные. В обсервационном исследовании случай-контроль за период с 01.01.2011 г. по 31.12.2018г. изучены результаты лечения лимфомы на фоне беременности. Разработан метод, включающий своевременное лечение данной неоплазмы на фоне беременности, не прерывая последнюю, при этом не ухудшая прогноз злокачественного новообразования и пролонгируя беременность до срочных родов. Результаты. 5-летняя общая выживаемость в основной группе пациентов с лимфомами составила

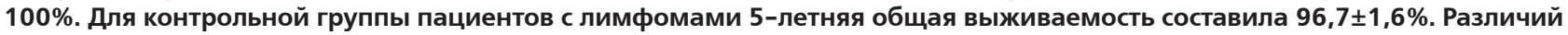
в общей выживаемости между сравниваемыми группами не наблюдалось $(p>0,05)$. Для контрольной группы 5-летняя бессобытийная выживаемость составила 83,3 $3,4 \%$; для основной $-90,2 \pm 6,6 \%(p>0,05)$. Таким образом, в основной группе при более длительном сроке наблюдения не отмечено статистически значимых различий в показателях выживаемости $($ (р>0,05). Этап лучевой терапии откладывался на послеродовой период, если был необходим. Заключение. Сравнительный анализ отдаленных результатов лечения по выживаемости не выявил статистически значимых различий в основной и контрольной группах $(p>0,05)$.

Ключевые слова: беременность; рак; родоразрешение; осложнения беременности; лимфома.

\section{ВВЕДЕНИЕ}

Только в Республиканском научно-практическом центре «Мать и дитя» и Республиканском научно-практическом центре онкологии и медицинской радиологии им. Н.Н. Александрова Республики Беларусь родоразрешается 150 беременных со злокачественными опухолями в год. У наибольшего числа беременных пациенток отмечают злокачественные опухоли щитовидной железы, на 2-м месте - лимфомы и рак шейки матки, на 3-м - рак молочной железы в сочетании с беременностью [1]. По данным литературы, отмечается два возрастных пика заболеваемости лимфомами - в 16 и в 35 лет [2]. Согласно данным Белорусского канцер-регистра, они приходятся на $30-34$ года и $70-74$ года.

Заболеваемость неходжкинской злокачественной лимфомой (НХЛ) не имеет возрастной зависимости, средний возраст на момент установления диагноза составляет 42 года [3].

После радикального лечения лимфомы Ходжкина вероятность излечения имеют почти $90 \%$ из всех заболевших. $60 \%$ женщин после излечения лимфомы пытаются иметь собственных детей, у $50 \%$ эти попытки успешны. Большинство рецидивов приходится на первые 2-3 года после окончания терапии [4].

\section{МАТЕРИАЛЫ И МЕТОДЫ}

В нашем исследовании проанализирована информация о 23 женщинах с лимфомой (лимфома Ходжкина и НХЛ), ассоциированной с беременностью, которые были пролечены с использованием системной химиотерапии (XT) во время гестации (основная группа). Контрольную группу составили 133 пациентки с лимфомой вне беременности. В группу сравнения вошли 74 здоровые беременные (без экстрагенитальной патологии, которые поступали в родильные отделения для родоразрешения с учетом критериев включения и исключения.
Возраст пациенток в группах варьировал от 18 до 44 лет, средний возраст в основной группе составил $32(24 ; 36)$ года, в контрольной $-29 \pm 6$ лет, в группе сравнения $-31 \pm 6$ лет. Исследуемые группы были сопоставимы по возрасту (p>0,05).

Распределение по паритету родов было следующим: основная группа: первородящие женщины составляли $30,4 \%$ (7 пациенток), повторнородящие - 69,6\% (16 пациенток), в группе сравнения: первородящие $-50 \%$ (37), повторнородящие $-50 \%$ (37).

Симптомы лимфомы были сходны с характерными признаками беременности (утомляемость, тошнота и рвота, уменьшение массы тела, боль в животе). Перечень диагностических процедур являлся стандартным: проводилась пункция и/или дальнейшая биопсия лимфатического узла с гистологическим исследованием. Операцию проводили под местной анестезией. При отсутствии поверхностно доступных лимфоузлов проводили общее обезболивание для выполнения эксцизионной биопсии. В целом, благодаря современным хирургическим и обезболивающим методам плановая операция у беременной является безопасной даже в I триместре. Уровень риска спонтанного аборта, материнской смертности, рождения ребенка с дефектами или позднего развития нервной системы статистически не отличается при проведении операций у беременных с лимфомами по сравнению с больными в популяции [5].

Распределение гистологических вариантов лимфом, диагностированных во время беременности, аналогично таким у небеременных. Среди лимфомы Ходжкина чаще диагностировали вариант нодулярного склероза. По НХЛ, ассоциированным с беременностью, - чаще всего диагностируют агрессивные типы НХЛ, а именно диффузную В-крупноклеточную и Т-клеточные лимфомы [2]. 
У большинства пациенток 76,70\% (21 женщина) выявлена лимфома Ходжкина, в 21,80\% случаев определяли НХЛ (2 пациентки).

После проведения диагностических мероприятий производили стадирование заболевания. Распределение пациенток по стадии заболевания представлено в табл. 1.

Контрольная и основная группы были сопоставимы по распространенности процесса (р>0,05) (см. табл. 1).

Как в основной, так и в контрольной группах более чем у половины пациенток 60,9\% (77 женщин) и 58,6\% (78 женщин) соответственно, диагностирована II стадия заболевания. Пациентки c IV стадией составили в основной группе $13 \%$ от общего числа, в контрольной $-11,3 \%$, с I стадией $17,4 \%$ и $14,3 \%$ соответственно. Наиболее редко отмечали III стадию - 2 пациентки $(8,7 \%)$ в основной и $20(15,0 \%)-$ в контрольной группах. Как видно из табл. 1, статистически значимых различий в распределении пациентов по клинической стадии заболевания не выявлено $(\mathrm{p}>0,05)$.

Статистический анализ проводился с применением программных пакетов STATISTICA 8.0, IBM SPSS 22. При анализе количественных значений в случае нормального распределения использовались параметрические методы статистической обработки и применялся t-критерий Стьюдента, к величинам не подчиняющимся нормальному распределению применялись непараметрические методы анализа.

\section{РЕЗУЛЬТАТЫ И ОБСУЖДЕНИЕ}

Во время беременности лимфома выявлена впервые у 28 пациенток. У $6(21,4 \%)$ больных - в III триместр, у $18(64,3 \%)$ - во II триместр, у $4(14,3 \%)$ - в I триместр. В основной группе $5(3,76 \%)$ пациенток категорически отказались от проведения полихимиотерапии во время беременности, лечение было отсрочено до родоразрешения (они были исключены из основной группы). 23 пациентки $(17,29 \%)$ (основная группа) получили лечение во время беременности, которое включало: ХТ от 1 до 4 курсов - 14 пациенток $(10,53 \%)$, и комплексное лечение - 9 пациенток $(66,77 \%)$. Этап лучевой терапии откладывался на послеродовой период.

Анализ течения беременности у пациенток с лимфомой позволил выявить осложнения у 7 женщин основной группы $(30,4 \%)$ и в группе сравнения у 37 больных (50\%) (табл. 2).

Наиболее часто отмечалась угроза преждевременных родов - 19\% (14 пациенток в группе сравнения $(\mathrm{p}<0,05))$. Мы объясняем данный факт тем, что пациентки с лимфомой психологически были настроены выносить беременность и родить, поэтому не предъявляли жалоб. Хотя и были преждевременные роды в основной группе, они были проведены на сроке 32-36 нед ввиду окончания курсов

Таблица 1. Распределение пациенток по стадии заболевания

\begin{tabular}{|c|c|c|c|c|c|}
\hline \multirow{3}{*}{ Стадия } & \multicolumn{4}{|c|}{ Группа пациенток } & \multirow{3}{*}{ P-value } \\
\hline & \multicolumn{2}{|c|}{$\begin{array}{c}\text { Основная, } \\
n=133\end{array}$} & \multicolumn{2}{|c|}{$\begin{array}{c}\text { Сравнения, } \\
n=133\end{array}$} & \\
\hline & $\mathbf{n}$ & $\%$ & $\mathbf{n}$ & $\%$ & \\
\hline I & 4 & 17,4 & 19 & 14,3 & $>0,05$ \\
\hline$\|$ & 14 & 60,9 & 78 & 58,6 & \\
\hline III & 2 & 8,7 & 20 & 15,0 & \\
\hline IV & 3 & 13,0 & 15 & 11,3 & \\
\hline Стадия не установлена & 0 & 0,0 & 1 & 0,8 & \\
\hline
\end{tabular}

Таблица 2. Осложнения течения беременности у пациенток с лимфомой

\begin{tabular}{|c|c|c|c|}
\hline \multirow{2}{*}{ Показатель } & \multicolumn{2}{|c|}{$\begin{array}{c}\text { Группа пациенток, } \\
\text { n (\%) }\end{array}$} & \multirow{2}{*}{ P-value } \\
\hline & $\begin{array}{c}\text { Основная, } \\
n=23\end{array}$ & $\begin{array}{c}\text { Сравне- } \\
\text { ния, } n=74\end{array}$ & \\
\hline Угроза прерывания & $0(0,0)$ & $14(18,9)$ & 0,036 \\
\hline Преэклампсия & $1(4,3)$ & $8(10,8)$ & 0,681 \\
\hline Преждевременные роды & $3(13,04)$ & $5(6,75)$ & 0,389 \\
\hline Гипоксия плода & $1(4,3)$ & $8(10,8)$ & 0,681 \\
\hline Отслойка плаценты & $0(0,0)$ & $1(1,35)$ & 1,000 \\
\hline Анемия железодефицитная & $3(13,04)$ & $5(6,75)$ & 0,389 \\
\hline Преждевременное излитие вод & $0(0,0)$ & $4(5,4)$ & 0,57 \\
\hline
\end{tabular}

ХТ и нежелания пациенток проходить системную ХТ в III триместр (табл. 2).

Представленные в табл. 3 данные свидетельствуют о том, что большая часть женщин $(78,3 \%)$ основной группы была родоразрешена в сроке 37-40 нед. В 4,3\% случаев были зарегистрированы выкидыши; родоразрешение до 32-й недели не наблюдалось. Полученные результаты статистически не отличаются от данных, полученных в группе сравнения: в срок 37-40 нед были родоразрешены 70 женщин $(94,6 \%)$, родоразрешение до 32 нед и выкидыши были верифицированы у 2 пациенток $(2,7 \%)$ в каждом случае $(\mathrm{p}>0,05)$.

Родоразрешены путем кесарева сечения 10 пациенток (44\%) с лимфомами. Необходимо отметить, что метод родоразрешения у всех пациенток определяли исключительно акушерской ситуацией. Наличие лимфомы на момент беременности или в анамнезе не являлось препятствием к родам через естественные родовые пути, за исключением ситуации, когда требовалось безотлагательно продолжать проведение полихимиотерапии, а пациентка не давала на это согласия во время беременности. Было принято решение провести роды досрочно на 33-34-й неделях с дальнейшим лечением. В силу абсолютной незрелости родовых путей и отсутствия времени на их подготовку, роды вели путем операции кесарева сечения. Медицинский аборт выполнен 1 пациентке $(3,01 \%)$, перинатальных потерь не было, не выявлены случаи рождения детей с врожденной и наследственной патологией (см. табл. 3). Сам диагноз лимфомы как в активной фазе, так и в ремиссии заболевания не является показанием для родоразрешения оперативным путем. Показаниями являются или необходимость немедленного начала противоопухолевого лечения при неподготовленных родовых путях, или осложнения, связанные со специальной терапией (постлучевой кардиофиброз, сердечно-легочная недостаточность II-III степени, асептический некроз тазобедренного сустава, переломы поясничного отдела позвоночника и др.).

При анализе полученных клинико-лабораторных данных в группе больных с лимфомой и здоровых беременных выявлены достоверные различия по уровню лейкоцитов, в основной и группе сравнения $-8,7 \pm 2,4,10^{9} /$ л и $11 \pm 4$, $10^{9} /$ л соответственно; $\mathbf{p}<0,05$ (см. табл. 3 ). Как видно из анализа клинико-лабораторных показателей, в основной группе не наблюдалось выраженной анемии и иммуносупрессии на фоне лечения химиопрепаратами (табл. 4).

Bсе пациенты основной группы получали с целью профилактики тромбоэмболических осложнений низкомолекулярные гепарины, при этом не выявлено достоверных различий в показателях коагулограммы в исследуемых группах (p>0,05) (см. табл. 4).

Новорожденные дети от матерей с лимфомами не имели тенденции к более низким параметрам физического развития по массе $-3327 \pm 436$ г ( $>0,05)$ и длине тела $52 \pm 3$ см $(\mathrm{p}>0,05)$ по сравнению с детьми здоровых женщин -3379 г и $52 \pm 3$ см соответственно, по шкале Апгар достоверных различий зафиксировано не было (8-10 баллов как среди новорожденных основной группы, так и среди здоровых женщин) (табл. 5). Все дети, рожденные у матерей данной основной группы, при рождении были практически здоровы и имели массу тела, соответствующую сроку беременности. Аномалии развития не зарегистрированы, психическое и физическое развитие соответствовало возрастной периодизации. Анализ характеристик детей в группах здоровых беременных и беременных

Таблица 3. Сравнительная характеристика пациенток основной группы согласно срокам и методам родоразрешения

\begin{tabular}{lcc}
\hline \multirow{2}{*}{\multicolumn{1}{c}{ Показатель }} & \multicolumn{2}{c}{ Количество пациенток } \\
\cline { 2 - 3 } & $\mathbf{n}$ & $\%$ \\
\hline Гестация до 32 нед & 0 & 0,0 \\
Гестация 32-36 нед & 3 & 13,0 \\
Гестация 37-40 нед & 19 & 78,3 \\
Выкидыш/медицинские показания & 1 & 4,3 \\
Кесарево сечение & 10 & 44,0 \\
\hline
\end{tabular}


Таблица 4. Клинико-лабораторные характеристики матерей на момент родоразрешения в группах здоровых беременных и беременных пациенток с лимфомой

\begin{tabular}{|c|c|c|c|}
\hline $\begin{array}{l}\text { Клинико-лабораторные характеристики матери } \\
\text { (момент родоразрешения) }\end{array}$ & Беременные с лимфомой, $\mathrm{n}=23$ & Здоровые беременные, n=74 & P-value \\
\hline $\begin{array}{l}\text { Возраст, лет, Ме (Q25; Q75), среднее } \pm \text { среднее квадратичное } \\
\text { отклонение (с.к.о.) }\end{array}$ & $32(24 ; 36)$ & $31 \pm 6$ & 0,956 \\
\hline Гемоглобин, г/л & $118 \pm 10,4$ & $122 \pm 9$ & 0,143 \\
\hline Лейкоциты, $10^{9} /$ л, среднее \pm с.к.о. & $8,7 \pm 2,4$ & $11 \pm 4$ & 0,041 \\
\hline Тромбоциты, $10^{9} / л, \mathrm{Me}(\mathrm{Q} 25 ; \mathrm{Q75})$ & $239(210 ; 261)$ & $226(199 ; 259)$ & 0,27 \\
\hline Скорость оседания эритроцитов, мм/час, среднее \pm с.к.о. & $36,8 \pm 12,4$ & $32 \pm 8$ & 0,086 \\
\hline Палочкоядерные, \%, среднее 士 с.к.о. & $5,2 \pm 2,1$ & $6(4 ; 7)$ & 0,265 \\
\hline Аланинаминотрансфераза, U/I, Me (Q25; Q75) & $25,7 \pm 16,6$ & $20(13 ; 26)$ & 0,447 \\
\hline Аспартатаминотрансфераза, U/I, Me (Q25; Q75) & $23(14 ; 28)$ & $21(16 ; 25)$ & 0,511 \\
\hline $\begin{array}{l}\text { Активированное частичное тромбопластиновое время, с, Ме } \\
\text { (Q25; Q75). }\end{array}$ & $\begin{array}{c}27,8 \\
(25,4 ; 28,2)\end{array}$ & $27,8 \pm 3$ & 0,5 \\
\hline Фибриноген, г/л, среднее \pm с.к.о. & $5,8 \pm 1,2$ & $6,1 \pm 0,9$ & 0,44 \\
\hline Международное нормализованное отношение, Мe (Q25; Q75) & $0,94(0,9 ; 1,1)$ & $0,97 \pm 0,08$ & 0,695 \\
\hline Протромбиновое время, с, Me (Q25; Q75) & $13(12,5 ; 14,4)$ & $13,7 \pm 0,9$ & 0,201 \\
\hline Активированный протромбиновый комплекс, среднее \pm с.к.о. & $108,6 \pm 23,1$ & $107 \pm 20$ & 0,731 \\
\hline
\end{tabular}

Таблица 5. Характеристики ребенка в группах здоровых беременных и беременных пациенток с лимфомой

\begin{tabular}{|c|c|c|c|}
\hline \multirow[t]{2}{*}{ Показатель } & $\begin{array}{c}\text { Беременные } \\
\text { с лимфомой, } \\
\mathrm{n}=233 \\
\end{array}$ & $\begin{array}{c}\text { Здоровые } \\
\text { беременные, } \\
\text { n=74 }\end{array}$ & \multirow[t]{2}{*}{ P-value } \\
\hline & n $\quad \%$ & $\%$ & \\
\hline $\begin{array}{l}\text { Масса новорожденного, г, } \\
\text { среднее } \pm \text { с.к.о. }\end{array}$ & $3327 \pm 436$ & $3379 \pm 561$ & 0,414 \\
\hline $\begin{array}{l}\text { Рост новорожденного, см, } \\
\text { Ме (Q25; Q75) } \\
\text { среднее } \pm \text { с.к.0. }\end{array}$ & $50(49 ; 53)$ & $52 \pm 3$ & 0,132 \\
\hline
\end{tabular}

пациенток с лимфомой, показал, что противоопухолевую терапию не следует противопоставлять беременности и родам, их можно успешно сочетать.

Таким образом, проведенное во время беременности лечение не ухудшило физического развития новорожденных.

Один из важнейших показателей эффективности проведенной терапии - это конечные результаты лечения, анализ общей выживаемости. Общая выживаемость в основной группе - 100\%, все живы. Для контрольной группы 5-летняя

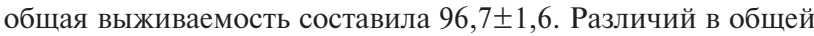
выживаемости между сравниваемыми группами не наблюдалось $(\mathrm{p}>0,05)$.

Была проанализирована бессобытийная выживаемость для сравниваемых групп. Для контрольной группы 5-летняя бессобытийная выживаемость составила $83,3 \pm 3,4$; для основной $-90,2 \pm 6,6$, Только у 3 пациенток из 23 отмечали рецидив. 1-летняя бессобытийная выживаемость у них состав-

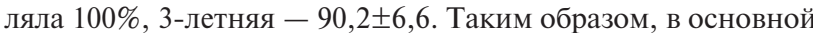
группе при более длительном сроке наблюдения отмечены статистически значимо лучшие показатели выживаемости $(\mathrm{p}<0,05)$ (рис. 1).

Диагноз лимфомы во время беременности создает проблемы для женщины, ее семьи и медиков. Вопрос сохранения беременности у таких больных до сих пор является дискуссионным и решается индивидуально.

Тактика ведения беременности при лимфоме зависит от трех основных факторов:

1) агрессивности лимфомы;

2) времени возникновения (I, II, III триместр);

3) желание женщины.

Существует три наиболее распространенных тактики ведения беременных с лимфомой: прерывание беременности, «watch and wait» (наблюдение и ожидание), лечение.

Сочетание беременности и лимфомы в ремиссии не служит показанием к прерыванию беременности. По нашим данным, наиболее простая ситуация, когда женщина хотела иметь ребенка после ремиссии в течение 3-5 лет. В данной ситуации не отмечалось достоверных различий в частоте осложнений течения беременности по сравнению с контрольной группой. Необходимо лишь бережное родоразрешение пациенток с лимфомами в анамнезе, так как эта беременность, возможно, единственная и часто долгожданная. Не наблюдалось достоверных различий в состоянии здоровья детей, рожденных от матерей со злокачественными новообразованиями (в частности лимфомами) и от здоровых беременных [1].

При рецидивирующем, агрессивном течении лимфомы или при впервые выявленной лимфоме запущенных стадий в I триместр показано прерывание беременности и проведение лечения основного заболевания. При отсутствии положительного эффекта от лечения лимфомы, угрозе жизни беременной показано прерывание беременности или досрочное родоразрешение на любом сроке.

Возможно проведение XТ во II и III триместры у пациенток, у которых впервые выявлена лимфома или имел место рецидив, а также у тех, которые отказались от прерывания беременности. А затем - родоразрешение в сроки жизнеспособного новорожденного. Ниже приведена примерная схема ведения пациенток с лимфомами [1] (рис. 2).

Большинство цитотоксических агентов проникают через плацентарный барьер и достигают плода благодаря их относительно малой молекулярной массе [6]. При лечении беременных с применением ХТ важно учитывать физиологические изменения, которые происходят во время беременности и могут снижать активную концентрацию препарата по сравнению с теми женщинами, которые имеют такую же массу тела, но не беременны. На сегодня фармакокинетические исследования у беременных, получающих XT, не проводились, они направлены на определение необходимой модификации доз цитостатических препаратов. Тератогенное действие многих

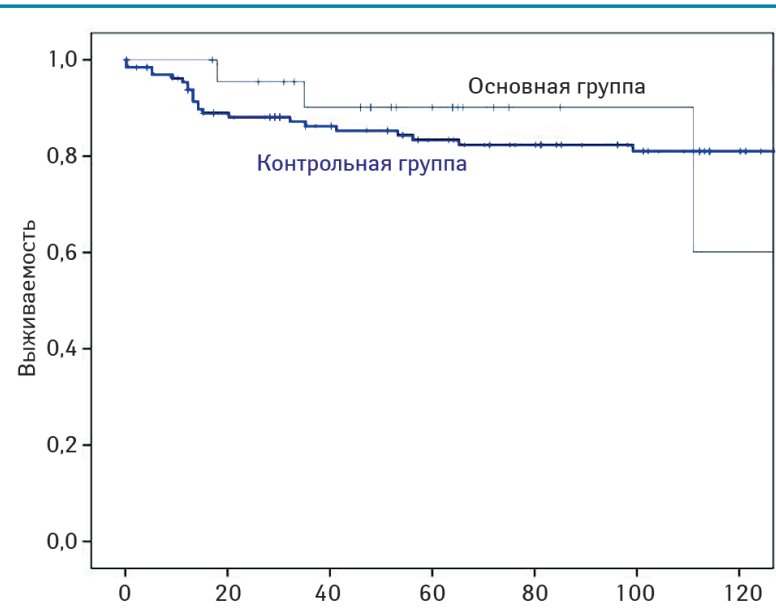

Рис. 1. Бессобытийная выживаемость в основной и контрольной группах 


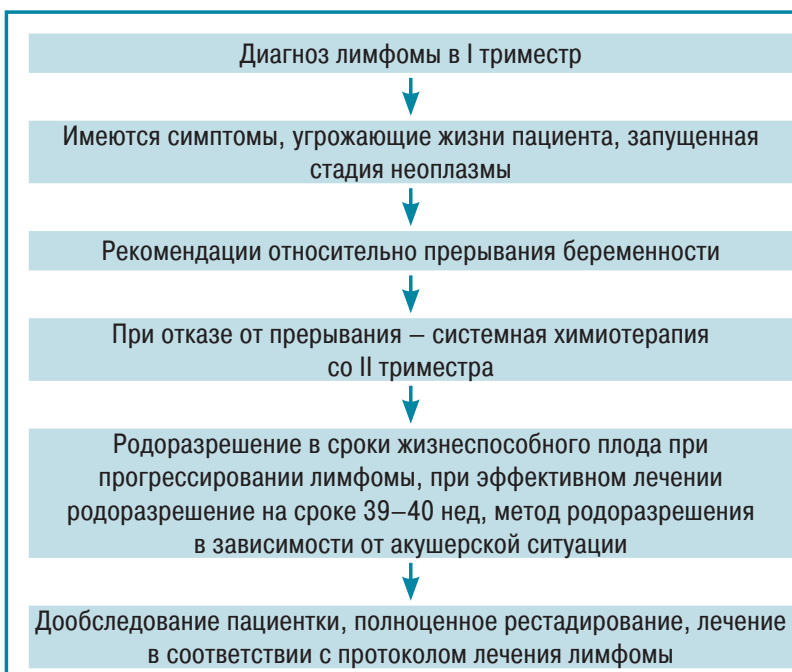

Рис. 2. Схема ведения пациентов с лимфомой

химиотерапевтических агентов документально подтверждено на животных [7].

XT в I триместр может повысить риск спонтанного выкидыша, привести к гибели плода и существенным порокам развития [8]. На возникновение пороков развития влияет гестационный возраст на момент облучения: плод чрезвычайно уязвим со 2-й по 8-ю неделю гестации, когда происходит органогенез [7]. Во время этого периода повреждения любого органа могут привести к смерти или значительным порокам развития плода. После завершения органогенеза остаются уязвимыми для ХТ центральная нервная система, кровь, орган зрения, репродуктивные органы [8]. Данный риск сохраняется на протяжении всей беременности, однако между 14-й и 16-й неделями беременности риск серьезных пороков развития или умственной отсталости значительно снижается [7].

В I триместр экспозиция к XТ ассоциируется с риском возникновения серьезных пороков развития на уровне 10-20\%. В целом, риск тератогенеза после лечения рака во II и III триместры беременности не ассоциируются с возникновением пороков развития, однако может возрастать риск неонатальной гибели плода, задержки внутриутробного развития, досрочных родов и малой массы тела при рождении $[6,8]$.

Решение об использовании ХТ во время беременности нами принималось с учетом побочных эффектов лечения, которые могут повлиять на материнскую выживаемость. Если это возможно, ХТ следует отложить до конца І триместра. Если же необходимо начать в I триместр беременности, решение о медицинском аборте следует рассматривать, учитывая мнение семьи пациентки.

\section{выводы}

Проведенный анализ полученных данных показал, что в современных условиях лечение лимфомы дает пациентам шанс на полное выздоровление и возвращение к полноценной жизни, в том числе - рождение ребенка. Противоопухолевую терапию не следует противопоставлять беременности и родам, их можно успешно сочетать. Проанализировав мировой опыт, накопленный по ведению беременности и родоразрешению пациенток с онкологической патологией и лимфомами, а также собственный опыт, предлагаем следующую тактику ведения беременных с лимфомами или перенесших данное заболевание ранее.

Если лимфома, как и другое онкологическое заболевание, диагностирована в I триместр, беременность следует прервать или начать специфическую терапию после 16 нед. Это обусловлено тем, что до 12 нед происходит формирование органов и систем, и влияние химиопре- паратов в этот период с большой вероятностью приведет к гибели плода или к тяжелым порокам развития. Отстрочив же XТ до II триместра (если пациентка отказывается от прерывания беременности), мы не поспособствуем тем самым прогрессу заболевания и не будем подвергать тератогенному риску плод.

В случае выявления лимфомы во II триместр наиболее эффективной тактикой является безотлагательное начало полихимиотерапии, поскольку от этого зависит прогноз исхода заболевания. Данный подход используют в большинстве мировых клиник. С целью профилактики миелосупрессии достаточно отменить ХТ за 3-4 нед до родоразрешения. Такую тактику применяют благодаря тесному сотрудничеству акушера-гинеколога и онколога. Важным является индивидуальный подход к каждой пациентке и каждой клинической ситуации. Необходимо максимально точно установить стадию злокачественного новообразования, так как подбор химиопрепаратов в данной ситуации будет несколько отклоняться от национального протокола, прописанного для того или иного вида лимфомы, в сторону более безопасных химиопрепаратов.

Следует отметить, что в случае выявления лимфомы в III триместр беременности, мы считаем целесообразным придерживаться такой же тактики, как и во II. Однако возможен и другой вариант: если не отмечен активный прогресс заболевания или пациентка отказывается от лечения во время беременности, можно дождаться срока жизнеспособности плода, произвести родоразрешение (желательно не ранее чем на сроке 32-33 нед) и после родов начать системную XT.

Оптимальным методом родоразрешения являются роды через естественные родовые пути, если позволяет акушерская ситуация. Лактацию мы считаем целесообразным прекратить, хотя существуют и обратные мнения.

Женщины, у которых лимфома находится в стадии ремиссии, должны использовать надежные средства контрацепции в течение 2 лет после ее достижения. Так как именно в этот период наибольшая вероятность рецидива заболевания. Нет данных, что беременность повышает риск рецидива. Прогноз дальнейшего течения болезни Ходжкина и НХЛ мало отличается у заболевших во время беременности от небеременных, у тех, у кого беременность наступила в период ремиссии, а также у тех, кто воздержался от беременности вовсе.

Таким образом, на сегодня в Республике Беларусь, как и во всем мире, женщины с диагнозом лимфомы могут реализовать свою детородную функцию с минимальными рисками для своего здоровья и для здоровья будущего ребенка. Это возможно при очень тесном сотрудничестве акушера-гинеколога и онколога, индивидуальном врачебном подходе к каждой клинической ситуации. Вопрос сохранения желанной беременности с минимальным риском у пациенток с онкопатологией важен еще и тем, что, несмотря на развитие широкого спектра репродуктивных технологий, уровень рождаемости и репродуктивный потенциал нации неуклонно снижается. В связи с этим необходимо приложить максимум усилий, чтобы найти компромисс между адекватным лечением пациенток и безопасным сохранением беременности.

\section{СПИСОК ИСПОЛЬЗОВАННОЙ ЛИТЕРАТУРЫ}

1. Андреева, Н. Л. (2016). Планирование, ведение беременности и родоразрешение пациенток с онкологическими заболеваниями: учеб. -метод. пособие. Минск: БелМАПО.

2. Amor, M. M., Olaso, A. S., Atienza, R., Stueben, B., Cohen, S., \& Kossev, P. (2013). Adult T-cell Leukemia Lymphoma during pregnancy. Medical Oncology, 2013, 631825. doi: $10.1155 / 2013 / 631825$.

3. Pentheroudakis, G., \& Pavlidis, N. (2006). Cancer and pregnancy: poena magna, not anymore. European Journal of Cancer, 42(2), 126-140. doi: 10.1016/j.ejca.2005.10.014.

4. Azim, H. A. Jr., Pavlidis, N., \& Peccatori, F. A. (2010). Treatment of the pregnan mother with cancer: a systematic review on the use of cytotoxic, endocrine, targeted agents and immunotherapy during pregnancy. Part II: hematological tumors. Cancer Treatment Reviews, 36(2), 110-121. doi: 10.1016/j.ctrv.2009.11.004.

5. Cohen-Kerem, R., Railton, C., Oren, D. Lishner, M, \& Koren, G. (2005). Pregnancy outcome following non-obstetric surgical intervention. The American Journal of Surgery, 190(3), 467-473. doi: 10.1016/j.amjsurg.2005.03.033. 
6. Weisz, B., Meirow, D., Schiff, E., \& Lishner, M. (2004). Impact and treatment of cancer during pregnancy. Expert Review of Anticancer Therapy, 4(5), 889902. doi: $10.1586 / 14737140.4 .5 .889$

7. Cardonick, E., \& lacobucci, A. (2004). Use of chemotherapy during human pregnancy. Lancet Oncology, 5(5), 283-291. doi: 10.1016/S1470-2045(04)01466-4.

8. Leslie, K., Koil, C., \& Rayburn, W. (2005). Chemotherapeutic drugs in pregnancy. Obstetrics and Gynecology Clinics, 32(4), 627-640. doi: 10.1016/j.ogc.2005.08.009.

\section{Лікування лімфом, асоційованих з вагітністю}

Н.Л. Андрєєва ${ }^{l}$, С.А. Мавричев ${ }^{2}$, А.В. Трухан

ДУО “Білоруська медична академія післядипломної освіти”,

Мінськ, Білорусь

ДУ “ Республіканський Науково-практичний центр онкології та медичної радіології ім. М. М. Александрова", Мінськ,

Білорусь

Резюме. Bcmyn. У сучасному світі активно вивчаються можливості ведення вагітності при раку, у тому числі і лімфомах. Мета дослідження. Оцінити можливості пролонгування вагітності при лімфомах. Матеріали та методи. Матеріалом для дослідження послужили відомості про 23 пацієнток з лімфомами, асоційованими з вагітністю, яким застосовували системну хіміотерапію під час гестації (основна група). Контрольну групу склали 133 пацієнтки з лімфомою поза вагітністю. До групи порівняння увійшли 74 здорові вагітні. В обсерваційному дослідженні випадок-контроль за період з 01.01.2011 p. до 31.12.2018 р. вивчені результати лікування лімфоми на тлі вагітності. Розроблено метод, що включає своєчасне лікування даної неоплазми на тлі вагітності, не перериваючи останню, при цьому не погіршуючи прогноз злоякісного новоутворення і пролонгуючи вагітність до термінових пологів. Результати. 5-річна загальна виживаність в основній групі пацієнтів з лімфомами становила $100 \%$. Для контрольної групи пацієнтів

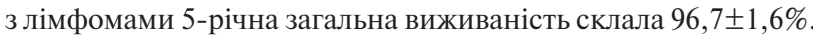
Відмінностей в загальній виживаності між порівнюваними групами не спостерігалося (p>0,05). Для контрольної групи 5 -річна безподієва виживаність становила $83,3 \pm 3,4$; для основної $-90,2 \pm 6,6$ (p $>0,05)$. Таким чином, в основній групі при більш тривалому терміні спостереження не відзначено статистично значущих відмінностей у виживаності $(\mathrm{p}>0,05)$. Етап променевої терапії відкладався на післяпологовий період, якщо був необхідним. Висновок. Порівняльний аналіз віддалених результатів лікування за виживаністю не виявив статистично значущих відмінностей в основній і контрольній групах $(\mathrm{p}>0,05)$.

Ключові слова: вагітність; рак; розродження; ускладнення вагітності; лімфома.
Treatment of pregnancy-associated lymphomas

N.L. Andreyeva ${ }^{1}$, S. A. Mavrichev ${ }^{2}$, A. V. Trukhan ${ }^{l}$

'SEE «Belarusian Medical Academy of Postgraduate Education", Minsk, Belarus

${ }^{2}$ State Institution «N. N. Alexandrov National Cancer Centre

Of Belarus", Minsk, Belarus

Introduction. In the modern world, the possibilities of pregnancy management in cancer, including lymphomas, are actively studied.

Objective. To analyze the possibility of prolonging pregnancy among women with lymphomas. Material and methods. as based on data on 23 patients with pregnancy-associated lymphomas who received systemic chemotherapy during gestation (the main group). The control group consisted of 133 patients with lymphoma outside pregnancy. The comparison group included 74 healthy pregnant women. In an observational case-control study for the period from 01.01 .2011 to 31.12 .2018 , the results of treatment of lymphoma during pregnancy were studied. A method has been developed that includes timely treatment of this neoplasm during pregnancy, without interrupting the latter, while not worsening the prognosis of malignancy and prolonging pregnancy until urgent delivery. Results. overall survival rate in the main group of patients with lymphomas was $100 \%$. For the control group of patients with lymphomas, the 5 -year overall survival was $96.7 \pm 1.6$. there were no Differences in overall survival between the compared groups $(\mathrm{p}>0.05)$. For the control group, the 5-year event-free survival rate was $83.3 \pm 3.4$; for the main group, the 5-year event-free survival rate was $90.2 \pm 6.6(p>0.05)$. Thus, there were no statistically significant differences in survival rates $(p>0.05)$ in the main group with a longer follow-up period. The radiation therapy stage was postponed until the postpartum period, if necessary. Conclusion. A comparative analysis of long-term treatment results for survival did not reveal statistically significant differences in the main and control groups $(\mathrm{p}>0.05)$.

Key words: pregnancy; cancer; delivery; pregnancy complications; lymphoma.

Aдpec:

Андреева Надежда Леонидовна

220000, Беларусь, г. Минск, ул. Леонида Беды, 45-329

E-mail:nadin1971@mail.ru 